\title{
MUESTRA DE UNA BIBLIOGRAFÍA COMENTADA DE HISTORIA DE LA LENGUA ESPAÑOLA
}

Francisco Abad Nebot

$U N E D$

«Apena pensar en cómo tenemos...

a nuestra Historia de la lengua»

Manuel Alvar

\section{PROPÓSITO}

Las páginas presentes (que quieren ser útiles para nuestros alumnos, y que hemos preparado como un símbolo mínimo de la voluntad de ayudarles), presentan distintas referencias bibliográficas analizadas adscribibles a la materia «Historia de la lengua española». No sólo por el argumento de autoridad (y para ello no hay nada más que ver el contenido de la Historia de Lapesa, o el de la Morfología histórica de Alvar), sino en primer término por la propia realidad empírica de los hechos estudiados, creemos que científicamente también integran la disciplina "Historia de la lengua» el análisis de la lengua literaria (española), la dialectología y la onomástica, y la historia de las ideas lingüisticas principalmente en cuanto nos testimonian acerca de hechos del pasado y en cuanto han incidido en la evolución real del idioma.

A partir de un total de unas 165 referencias que habíamos preparado seleccionamos algo menos de la tercera parte de ellas para publicarlas; además queremos advertir:

a) Se trata de manera explícita de una «muestra», de algo muy parcial por tanto; no ha de echarse en falta, pues, ningún titulo. Procuramos 
- referirnos -eso sí- a los diferentes capítulos que hemos identificado en la materia, y que acaban de quedar aludidos.

b) No mencionamos ninguno de los escritos de Menéndez Pidal, ya que todos los que hemos llegado a encontrar que escribió de lingüística los tenemos analizados uno a uno en la Biografia del maestro coruñés que se ha preparado bajo la dirección del profesor Rafael Lapesa.

Nuestra actual tarea es modesta, pero no creemos que ociosa; la experiencia nos dice que cosas que se imaginarían sabidas por los profesionales $\mathrm{y}$ los estudiantes no todos las saben. Ya hemos recogido unas palabras en que M. Alvar manifiesta cómo ve él la situación de la disciplina; desde luego existen profesores jóvenes o en la primera madurez valiosos, pero el estado del saber siempre nos exige un esfuerzo a todos. Alvar también ha escrito: «Se prevarica... y nadie se preocupa para que... el mozo estudie».

\section{BIBLIOGRAFIA}

1. Alarcos Llorach, Emilio, «Esbozo de una fonología diacrónica del español», Estudios dedicados a Menéndez Pidal, II, Madrid, CSIC, 1951, pp. 9-39.

Aunque la exposición clásica de Alarcos es la del cap. IX de su Fonología española («Fonología diacrónica del español»), no por ello debe olvidarse este artículo inicial, que contiene junto a la descripción de los hechos citas documentales antiguas de valor cierto.

2. Alonso, Amado, Estudios lingüísticos. Temas españoles, Madrid, Gredos, $1961^{2}$.

Este volumen que todo estudioso y aún estudiante ha consultado una o muchas veces, reúne los escritos que ahora nos impor- 
tan «La subagrupación románica del catalán», "Partición de las lenguas románicas de Occidente», "Una ley fonológica del español», «Substratum y superstratum», etc. Obra clásica que nunca dejará de serlo.

3. Alonso, Amado, De la pronunciación medieval a la moderna en español, Madrid, Gredos, I, 1967²; II, 1969.

«Ilumina y puntualiza el proceso de transformación fonológica de nuestra lengua, culminado a lo largo de los siglos XVI y XVII. La riqueza de materiales y la finura de su interpretación hacen de este [tratado] instrumento indispensable para entender el sistema fonológico del español antiguo» (Rafael Lapesa).

4. Alonso, Dámaso, «Estudios lingüisticos peninsulares», $O . C$., I, Madrid, Gredos, 1972.

«La contribución de Dámaso Alonso a la historia lingüística peninsular ponía en juego su amplio conocimiento de la dialectología hispana y de la lingüística románica... Analizaba hipótesis e interpretaciones, desmontaba, señalaba sus puntos valederos y sus puntos flacos, proponía en su caso soluciones nuevas... Desde los Origenes del español de Menéndez Pidal, nada tan importante [como Temas y problemas de la fragmentación fonética peninsular] se ha publicado sobre la historia de las lenguas peninsulares» (Rafael Lapesa).

5. Alvar, Manuel, Toponimia del alto valle del rio Aragón, Zaragoza, CSIC, 1949.

Tirada aparte - en realidad - de la revista Pirineos que incluye un estudio en el que su autor se ha propuesto «situar cada fenómeno dentro del cuadro de la dialectología aragonesa», y que documenta así estos rasgos:

«o > uá

$a$ sin inflexionar por yod de $x$

Mantenimiento de F- inicial 
$\mathrm{J}->c h$

Conservación de oclusiva sorda intervocálica

Sonorización de oclusiva sorda tras nasal

Asimilación de -ND- $>n$

Disimilación -RR- $>r d$ )

6. Alvar, Manuel, El romancero. Tradicionalidad y pervivencia, Barcelona, Planeta, $1974^{2}$.

En este volumen se propone la recogida de materiales romanceriles en tanto "tarea complementaria" de las clases de Historia de la lengua, se analizan algunos «medios expresivos» (elocutivos) y la "transmisión lingüística» en el romancero, se atiende a «el mundo sefardí» - otro componente de lo hispánico-, etc.

7. Alvar, Manuel, ed., Libro de Apolonio, Madrid, Castalia, 1976.

Incluye un «Estudio lingüistico» del texto y las "concordancias" del mismo. Algunos de los hechos atendidos los han interpretado de otra manera estudiosos distintos.

8. Alvar, Manuel, «Cuestiones de bilingüismo y diglosia en el español", en El castellano actual en las comunidades bilingües, Universidad de Salamanca, 1986, pp. 11-48.

Artículo en el que se sintetizan distintos fenómenos que muestran la complejidad real de situaciones de la comunidad castella- 
nohablante, y se propone para el caso de la lengua española: «Consideraré bilingüismo al conocimiento del castellano y otra lengua y a sus mutuas interferencias, mientras que la utilización simultánea de la lengua nacional y de un dialecto (leonés, aragonés, andaluz, etc.) lo consideraré como diglosia».

9. Alvar, Manuel, Estudios de geografia lingüistica, Madrid, Paraninfo, 1991 [pero 1990].

Reunión de las páginas respectivas en que el autor fue presentando los proyectos de sus Atlas (ALEA, ALEICan., ALEANR, $A L E S$, de Hispanoamérica, etc.) más estudios a partir de los materiales conseguidos sobre dialectología y cultura popular en Andalucia, Canarias, ... Útil volumen que ha resultado de tareas que sin un empeño de trabajo no se habrían llevado a cabo.

10. Badia Margarit, A. M., «Por una revisión del concepto de "cultismo" en fonética histórica», Studia hispanica in honorem $R$. Lapesa, Madrid, Gredos, I, 1972, pp. 137-152.

Lo que quiere argumentar el autor se encuentra perfectamente resumido en el párrafo último del artículo (p. 152), en el que se indican distintos factores que han de tenerse en cuenta "cada uno de los cuales puede dar razón de ciertas anomalías en los cambios de sonidos, sin que nos veamos obligados a recurrir a la "presión culta"». Uno de tales factores consiste en "la solución correspondiente a distintas zonas geográficas, que no han de coincidir todas en un tratamiento único". Se trata de un trabajo inteligente al que debe prestarse atención.

11. Bassols de Climent, M., Sintaxis histórica de la lengua latina. Las formas personales del verbo, Barcelona, CSIC, 1948.

«He dado - manifiesta el autor- ... relieve a los fenómenos sintácticos de las lenguas romances... La sintaxis de nuestra lengua es en muchos aspectos una continuación de la latina. La explica- 
ción última de muchos giros y construcciones hoy en día en uso, debemos buscarla en el latín vulgar y a veces incluso en el clásico». En este sentido la consulta de esta obra resulta necesaria; al final de la misma aparece incluso un «Índice de autores románicos» mencionados.

12. Bastardas Parera, Juan, Particularidades sintácticas del latin medieval, Barcelona, CSIC, 1953.

Riguroso análisis de documentación notarial que complementa perfectamente los Orígenes... de Menéndez Pidal. «Se encuentran en [estos documentos] - advierte Bastardas-gran cantidad de innovaciones pertenecientes a la lengua hablada del periodo en que fueron redactados. Ello hace posible el estudio documental de los fenómenos sintácticos propiamente románicos, mucho antes de la aparición de los primeros textos literarios".

13. Cano Aguilar, Rafael, El español a través de los tiempos, Madrid, Arco/Libros, 1988.

Esta obra -dice en su «Presentación» el autor, un alumno de Rafael Lapesa-, «va dirigida a estudiantes extranjeros y españoles, que quieran disponer de una síntesis clara y precisa de los hechos y problemas planteados en la evolución de nuestra lengua. Éste es su... objetivo: resumir lo que se sabe hoy de la historia del español, y mostrarlo en forma nítida y asequible».

14. Castro, Américo, Lengua, enseñanza y literatura, Madrid, V. Suárez, 1924.

Este tomo agrupa los ensayos «Evolución de la lengua española», «El habla andaluza», «Los galicismos», etc., que nos dan imagen muy bien del primer Américo Castro, el catedrático de filología y a la vez intelectual importante de la España de la «Edad de Plata». 
15. CASTRO, Américo, La peculiaridad lingüistica rioplatense y su sentido histórico, Madrid, Taurus, $1960^{2}$.

Ensayo cuyo sentido explica perfectamente su autor en las páginas preliminares: «Absorbido por otras tareas, no me ocupo ya de cuestiones de lenguaje con finalidades puramente lingüísticas. El lenguaje me interesa como expresión y síntoma de situaciones humanas, no en sí mismo».

16. Catalán, Diego, El español. Origenes de su diversidad, Madrid, Paraninfo, 1989.

Ordenación de trece trabajos previos según la coherencia de tres secciones: «Orígenes del pluralismo normativo del español de hoy", "Dinamismo de los sistemas lingüísticos», y "Nájera frente a Burgos»; los dos primeros de estos títulos apuntan bien la concepción que posee el autor. Páginas densas e inteligentes, que se continúan en Las lenguas circunvecinas del castellano, Madrid, $\mathrm{Pa}$ raninfo, 1989.

17. Criado de Val, M., El verbo español, Madrid, Saeta, 1969.

Refundición de sus trabajos anteriores que hacen calas en la historia del sistema verbal castellano; sugerencias aprovechables.

18. DiAZ Y DiAZ, Manuel C., Las primera glosas hispánicas, Barcelona, Universidad Autónoma, 1978.

«En un punto incierto de la Rioja-Este de Burgos (escribe el autor), en los primeros decenios del siglo XI, en una escuela clerical o monástica..., algunas personas glosaron unos folios... sustituyendo las glosas latinas usuales, que manejaron y con las que contaron como fundamento, por interpretaciones románicas, llegando a traducir una doxología». Es un trabajo que «abre insospechadas perspectivas» (R. Lapesa). 
19. Diaz-Plaja, Guillermo, Historia del español, Barcelona, La Espiga, 1941.

Completado con unas Lecciones de «Fonética y Gramática histórica» a cargo de Rafael Ferreres, este manual de enseñanza media no deja de tener algún interés para el estudioso, que puede ver en el mismo cuál era en 1941 el estado de las cuestiones, o qué matices propios introducían dos investigadores jóvenes que luego iban a adquirir relieve personal.

20. Dónoam y otros autores, Joan Coromines, Barcelona, Anthropos, 1990.

«Perfil biográfico» de Coromines más tres comentarios respectivos a sus tres obras magnas. Impresiona y emociona la entrega al estudio de este catalán, el segundo de los hijos del conocido escritor Pere Coromines.

21. GarCía de Diego, Vicente, Gramática histórica española, Madrid, Gredos, $1970^{3}$.

Gramática histórica que se propone no dejar de recoger «las formas... de los dialectos absorbidos por el castellano cuyas voces perduran y son por tanto patrimonio de la lengua castellana». Asimismo incluye observaciones sobre «Sintaxis».

22. García de Diego, V., «El castellano como complejo dialectal y sus dialectos internos», RFE, XXXIV, 1950, pp. 107-124.

Lo enunciado en el título significa asimismo que «el español es dialectalmente pobre frente al francés y al italiano, y es más rico en dialectalismos" (p. 107). 
23. Gómez-Moreno, Manuel, Misceláneas. La Antigüedad, Madrid, CSIC, 1949.

Extenso volumen que refunde muchos trabajos de su autor; reunión de páginas algunas de ellas señeras en la marcha de la investigación, entre las que se encuentran -por lo que ahora a nosotros nos importa - las dedicadas a las lenguas hispánicas de la Antigüedad, y las que abordan toda la temática del iberismo.

24. González Calvo, José Manuel, La prosa de Ramón Pérez de Ayala, Universidad de Salamanca, 1979.

Logrado análisis del discurso en prosa de un autor relevante, y que atiende tanto al léxico como a la propia articulación o estructura prosística.

25. González Olle, Fernando, "Aspectos de la norma lingǘstica toledana", Actas del I Congreso Internacional de Historia de la Lengua Española, Madrid, Arco /Libros, 1988, I, pp. 859-871.

El autor expone su convencimiento de que «la norma lingüística toledana procede de un núcleo histórico de carácter legal»; modifica así - aunque no lo subraye de manera explícita - su opinión de un trabajo anterior.

26. GonzÁlez Olle, Fernando, «Primeras noticias y valoraciones del andaluz», BRAE, LXVII, 1987, pp. 347-387.

Historia de la historiografia sobre el habla andaluza, referida a los testimonios de los primeros siglos modernos.

27. Gracián Dantisco, Lucas, Galateo español, ed. por M. Morreale, Madrid, CSIC, 1968.

Edición y anotación con detalle y rigor de un texto cuyo conocimiento por parte de Cervantes (han dicho varios autores $y$ 
escribe en particular F. Márquez Villanueva) «no puede ser puesto en duda»

28. Guillén, Claudio, Teorias de la historia literaria, Madrid, EspasaCalpe, 1989.

Nos referimos a este volumen porque en el mismo se plantea explícitamente el problema del cambio literario, y su consideración resulta ilustrativa para atender y entender el cambio lingüístico.

Guillén se manifiesta de esta manera: "Al historiador de la literatura le interesan aquellos sistemas o aquellas estructuras...que intervienen, que aparecen, que suceden, en el devenir histórico [...] Nuestro historiador ideal de la literatura seria...un «diacronicista estructural», o si se prefiere por motivos verbales, un estructuralista diacrónico».

Volumen inteligente y culto.

29. LAPESA, Rafael, «La toponimia como herencia histórica y lingüistica», Las Ciencias, XXXIV, 1969, pp. 239-251.

Informe, en un tono de presentación general pero sólido, acerca de «el valor auxiliar de la Toponimia para la Historia general y más aún para la Historia lingüística», y que señala además los nombres de lugar en cuanto «índice de la relación entre el hombre y el suelo».

30. LAPESA, Rafael, "Comunidad lingüística y diversidad nacional en la cultura hispánica», en Actas del Simposio sobre Posibilidades y limites de una historiografia nacional, Madrid, Instituto Germano-Español de Investigación, 1984, pp. 525-533.

Bella ponencia sobre la forma interior de la lengua, los nombres del idioma, etc., en el marco de lo que es la tradición cultural nacional.

Por lo que respecta a los cambios en la forma interior lingüistica escribe concretamente nuestro autor: «El español medieval... 
distribuia de otra manera los usos de haber y tener, haber y ser, ser y estar; desconocía las construcciones impersonales se está bien aquí, se castiga a los culpables; no había generalizado el uso de la preposición a con el objeto directo personal; se resistía...a emplear artículo ante nombres tomados en sentido genérico, abstractos, de materia, colectivos, etc., y ante plurales representativos de clases o grupos; era muy parco en combinar con el neutro lo adjetivos calificativos».

31. LAPESA, Rafael, «Orígenes y expansión del español atlántico», en Acto académico de investidura como doctores "honoris causa" a los Exmos Sres D. Rafael Lapesa [y] D. Manuel Lainz, Universidad de Oviedo, 1988.

Revisión y actualización del problema de los orígenes de la norma de Sevilla cuya novedad está en «conceder importancia a la herencia leonesa en la Andalucía occidental y - sobre todoal ceceo mozárabe sevillano-algarbeño del siglo XII» (comunicación personal del prof. Lapesa).

32. Lázaro Carreter, Fernando, La prosa de arte en lengua española, Univ. Autónoma de Madrid, 1988.

Original de un discurso - el título que le damos está sacado del propio texto, ya que en letra de imprenta sólo se dice «Discurso»-, en el que el prof. Lázaro sintetiza sus averiguaciones monográficas en torno a la escritura de don Juan Manuel, Guevara, Fray Luis, Valle-Inclán...

33. LidA, María Rosa, Selección del "Libro de Buen Amor" y estudios críticos, Buenos Aires, Eudeba, 1973.

Precioso volumen lleno de sabiduria, y que en su «Indice de temas» orienta hacia los aspectos ligǘsticos tratados. 
34. LoPE BlANCH Juan M., Investigaciones sobre dialectologia mexicana, México, Universidad Nacional Autónoma, 1979.

Reunión de estudios en torno al problema del polimorfismo de las hablas mexicanas, sobre lo que escribe el autor: "Las formas concurrentes ya sean fonéticas, morfosintácticas o lexicológicas, son realidad inherente a toda lengua hablada...Negar la variación libre en aras de incuestionables variaciones condicionadas, es negar la evidencia».

35. LoPE BlanCh, Juan M., El estudio del español hablado culto. Historia de un proyecto, México, Universidad Nacional Autónoma, 1986.

Historia - en efecto- y pasos dados y logros obtenidos en el «Proyecto de estudio coordinado de la norma lingüistica culta de las principales ciudades de Iberoamérica y de la Península Ibérica». Lope señala la relevancia de este análisis: «És de gran interés... dar a conocer las modalidades generales urbanas, que muchas veces descubren las tendencias evolutivas hacia las que apunta la lengua... No se [incurrirá] así por ejemplo en el error de tratar de enseñar al estudiante un paradigma verbal - muy completo y muy "clásico"-, que no se corresponde al uso de los países iberoamericanos (ni tampoco al peninsular de nuestros días)".

36. Navarro, Tomás, Documentos lingüisticos del Alto Aragón, Syracuse, Syracuse University Press, 1957.

Volumen que iba a formar parte - como se sabe- de la serie de «Documentos lingüísticos de España» emprendida por la escuela de Menéndez Pidal; en concreto, «uno de los libros fundamentales de la filología española" (Joan Corominas). Cfr. en efecto J. Corominas, Tópica Hespérica, Madrid, 1972, I, pp. 186 ss.

37. Navarro Tomás, T., Capitulos de geografia lingüistica de la Península Ibérica, Bogotá, Caro y Cuervo, 1975.

«Noticia histórica del $A L P I »$ más siete estudios compuestos a partir de sus materiales. Precioso testimonio tanto documental como historiográfico. 
38. Niederehe, Hans-J., Alfonso $X$ el Sabio y la lingüistica de su tiempo, trad. esp., Madrid, SGEL, 1987.

La más completa monografia de que disponemos acerca de la conciencia lingüística del rey Alfonso, imprescindible en su consulta aunque como en toda obra algún asunto se pueda ampliar o matizar. Es lástima que distintos desajustes de imprenta hayan inutilizado varias referencias a las fuentes y los textos.

39. Oliver Asín, Jaime, Historia de la lengua española, Madrid, MCMXL4.

Historia un tanto olvidada desde la evidentemente superior de Lapesa, pero con apuntes sugerentes y que -creemos-, todo profesional debe conocer.

40. París, Carlos, «Razón y experiencia en la metodología de los modelos", Homenaje a Xavier Zubiri, Madrid, Moneda y Crédito, 1970, II, pp. 461-473.

Mencionamos este escrito de teoría de la ciencia porque resulta muy útil para entender la diferencia entre una lingüistica que se ocupe de la sincronía estándar de la lengua, y otra que trate además de la variedad dialectal y diacrónica de la misma. Por supuesto es un artículo de carácter general, y la aplicación a lo idiomático ha de hacerla el lector.

41. Pottier, Bernard, «La evolución de la lengua aragonesa a fines de la Edad Media», $A F A$, XXXVIII, 1986, pp. 225-240.

Traducción por Pilar García Mouton de un antiguo y conocido artículo (de 1952), que argumenta acerca de uno de los procesos importantes de la historia de nuestra lengua. 
42. Rosenblat, Ángel, Los conquistadores y su lengua, Caracas, Universidad Central de Venezuela, 1977.

Planteamiento del punto de vista del autor acerca de «la base del español americano», más referencias al proceso de «la hispanización de América». Se trata de fragmentos de un proyectado libro sobre el español de América que don Ángel no llegó a redactar y terminar.

43. SEco, Manuel, Estudios de lexicografia española, Madrid, Paraninfo, 1987.

Reunión de un pulcro texto sobre "Los diccionarios históricos» más otros referidos a los diccionarios españoles en su historia. Bello y necesario volumen.

44. Senabre, Ricardo, "Estructuras mnemónicas en la poesía de Espronceda", Revista de Estudios Extremeños, XXXIV, 1978, pp. 5-20.

«Un análisis literario de esta naturaleza -manifiesta Senabre - permite conocer el tipo de fórmulas que selecciona un escritor y el modo de operar de su "memoria" - hay casos en que predominan las estructuras mnemónicas rítmicas, frente a otros en que lo decisivo son fórmulas léxicas o gramaticales».

45. Senabre, Ricardo, "Aspectos fónicos en la poesía de fray Luis», Academia Literaria Renacentista, I, Universidad de Salamanca, 1981, pp. 249-269.

Análisis de algunos aspectos del idiolecto o gramática poética luisiano, y de la expresividad conseguida con el significante. Trabajo de finura sobresaliente. 
46. Tovar, Antonio, Latin de Hispania: aspectos léxicos de la romanización, Madrid, Real Academia Española, 1968.

Texto de un discurso «sobre qué palabras latinas caracterizaron desde el principio el latín de la Península, y cómo se estableció en ella la continuidad ininterrumpida que pervive hoy en los labios de castellanos, catalanes, portugueses, como herencia de la colonización».

47. Vossler, Karl, Filosofia del lenguaje, trad. esp., Buenos Aires, Losada, 1943.

A pesar de que por el título podría no parecerlo, esta obra trata del cambio lingüístico, con variados ejemplos del mundo románico. Una lectura instructiva y creemos que necesaria; el volumen ha sido tenido en cuenta a veces más de lo que se suele confesar.

48. Zamora VICENTE, Alonso, Lengua, literatura, intimidad, Madrid, Taurus, 1966.

Volumen misceláneo con algún sugestivo planteamiento literario, y que aborda asimismo cuestiones idiomáticas y de lengua artística.

49. Zamora Vicente, Alonso, Dialectologia española, Madrid, segunda ed. muy aumentada, Gredos, 1967.

"Sintesis bien informada y claramente expuesta... Aunque excelente en su género, esta útil y cuidadosa compilación pone de manifiesto las limitaciones y la inconsistencia de la dialectología comparativa, que sólo se interesa en inventariar los rasgos "aberrantes" de los dialectos y que no se preocupa ni de describir la estructura y funcionamiento de los dialectos estudiados, ni de precisar las relaciones (sincrónicas y diacrónicas) de los varios dialectos entre sí y con la lengua patrón» (Diego Catalán). 
50. ZAMORA ViCEnTE, Alonso, La realidad esperpéntica, Madrid, Gre'dos, 1974 '.

Incluye un capítulo sobre la lengua, que deberá complementarse con las notas léxicas que el propio autor ha puesto a su edición de Luces... (en "Clásicos Castellanos»).

Según dijimos al inicio hemos analizado en realidad sólo una muestra de la mucha bibliografia existente; a los alumnos deben presentarse asimismo de manera muy principal las fuentes para el estudio de la lengua: por ejemplo, deberá presentarse el decisivo acopio léxico y gramatical que supone el Diccionario de construcción y régimen... de Rufino José Cuervo. De igual modo existen en el mercado guías pedagógicas con propuestas de ejercicios: así Francisco Marcos (El comentario lingüistico) ha mostrado un diseño de "comentario filológico", ejercicio que "al comentario de textos... une ahora el reconocimiento de los fenómenos de todo tipo que permiten fecharlo e identificarlo del modo más aproximado".

Como puede verse, hemos reproducido a veces el juicio y la estimación de otros autores; es práctica conocida que tiene lugar cuando se coincide en tal juicio al hacer el análisis del trabajo de que se trate. Nosotros hemos procurado ofrecer en estas ocasiones alguna valoración que - además de ser relevante- resulta no siempre accesible.

SOBRE LA HISTORIA DE LA LENGUA Y EL CAMBIO LINGÚíSTICO

Debemos a Roman Jakobson la insistencia en que la sincronía lingüística no supone un estatismo o uniformidad del código comunicativo: la sincronia implica diferenciación interior, variabilidad en el seno de la comunidad hablante. Nuestro autor lo expresó con la analogía del cine: "Cuando en una película -escribió- yo le pregunto qué ve $\mathrm{Vd}$. en un momento dado en la pantalla, no ve figuras estáticas; verá caballos al galope, gente que pasea y otros movimientos".

Cualquier momento dado en la comunidad hablante no significa que un código estrictamente uniforme y uniformemente distribuido se dé en ella, sino que la realidad nos muestra un diasistema lo suficientemente unitario como para permitir la intercomprensión y como para determinar la iden- 
tidad propia de un idioma, pero a la vez en parte escindido y diferenciado; la sincronía de la lengua resulta en efecto como la sincronía del cine: implica equilibrio inestable, movimientos, resultados que se consolidarán y difundirán o no, etc.

La sincronía interior de una comunidad lingüistica están de acuerdo distintos autores que presenta tres clases de variaciones: geográficas o diatópicas, sociales o diastráticas y de estilo (familiar, cuidado, académico, ...); la variabilidad de los productos idiomáticos según estas clases de diferencia dan al estado interior de la lengua un carácter de "diasistema», de conjunto de coincidencias y de parciales disimilitudes.

El inicio de la variación y del cambio lingǘsticos se halla pues en la propia estructura de la comunidad de idioma; una variación inicial bien delimitada geográfica o socialmente o bien de estilo, puede asentarse y difundirse, y entonces se habrá producido el «cambio lingüístico», cambio que puede llegar hasta toda la comunidad global o a un sector de ella. Un posible cambio idiomático es al inicio una variación y diferenciación de estilo que coexiste con otros estilos; si la variación inherente al lenguaje se propaga y nivela, se habrá producido entonces el cambio en la comunidad o subcomunidad de habla. «Las dos fases de un cambio en curso fueron reinterpretadas [en la lingüística europea de entreguerras] como dos estilos de lengua simultáneos; se concibió el cambio como un hecho de lingüística sincrónica, y como todo hecho de sincronía, exigió una comprobación de fines y medios con respecto a todo el sistema de la lengua» ( $R$. Jakobson).

En cualquier estado de una lengua - ha mantenido también por su parte Diego Catalán - la estructura lingüística no puede ser considerada ni homogénea ni estática; ello es así y los procesos de cambio idiomático significan la coexistencia de estilos diferenciados de hablar. Toda lengua comprehende un conjunto de subcódigos que la hacen ser diferenciada interiormente y consistir por tanto en un "diasistema»; la descripción ha de hacerse cargo pues de esta complejidad, de las diferencias sociales, de estilo o geográficas que podrían llegar a estandarizarse y a hacerse un cambio, etc. Según el enfoque del mismo Jakobson, «el principio y el final de todo proceso de mutación coexisten en la sincronia... Ninguna lengua puede ser descrita de forma plena y adecuada sin una visión de sus cambios en curso"s.

Creemos que Manuel Alvar se hace eco de las proclamas de Roman Jakobson cuando al comentar la incidencia de las variables sociales en la efectiva variación idiomática, escribe este párrafo:

«En esos sistemas inestables que son la lengua y la sociedad actuarán simultáneamente las fuerzas que llevan...al desmembramiento. Tal es el problema con que se encara el estructuralismo actual:...la revisión de la hipótesis monolítica del lenguaje...Estamos...ante un principio de 
diferenciación surgido de los propios hechos sincrónicos; habrá que encararse pues con todas las motivaciones sociales que han condicionado la fragmentación incipiente».

Toda lengua considerada en abstracto, ajena a su instalación efectiva en geografias y grupos sociales de la comunidad y como si no pudiera ser usada según estilos diferentes, constituye un ente de razón que sólo de modo parcial se corresponde con la realidad; la ciencia idiomática se ve alejada de su necesario contenido empírico si nada más se consideran hablantes «ideales", pues todo hablante es real y complejo. La racionalidad se dice que es compleja; la racionalidad del análisis lingüístico requiere que se considere toda la complejidad empírica con que se manifesta cualquier lengua humana.

En las lenguas se dan condiciones generales para que puedan producirse uno o varios cambios idiomáticos, pero ello no lleva de manera necesaria a su cumplimiento; si una innovación se difunde y nivela por todo el conjunto de los hablantes estaremos en efecto ante el cambio lingüístico, pero tal difusión y generalización es un proceso histórico y cultural. Diego Catalán ha insistido en este hecho: la coexistencia de subsistemas en el estado natural de cualquier lengua, es decir ( $y$ de otra manera), la generalización de las variaciones idiomáticas en tanto un proceso social e histórico cuyo cumplimiento ha de analizarse en concreto en cada caso; lo cultural es individual y específico, a diferencia y distancia de la generalidad necesaria de los fenómenos del mundo de la Naturaleza. «En las lenguas naturales (escribe Catalán) las dos estructuras - vieja y nueva - conviven durante largo tiempo (muchas veces plurisecularmente)...Si el cambio se inicia con la aparición de una variable en un determinado subgrupo de una comunidad lingüística (mutación), el proceso sólo termina (selección) cuando desaparece la variación, sea por el olvido de la variante nueva, sea por su elevación a la categoría de constante (en toda la comunidad o en un área dialectal fija). $Y$ este proceso rico en vicisitudes es evidentemente de naturaleza sociolingüistica».

La lengua en definitiva posee una naturaleza de "sistema de sistemas»; el análisis geográfico-lingüístico o el sociolingüístico bien muestran la concurrencia de subsistemas que se dan en la comunidad parcial o global de un idioma. Los dialectos asimismo resultan suprasistemas o sistemas de sistemas, se ha dicho, y es que en efecto cualquier código idiomático no es nunca monolítico ni está uniformemente distribuido dentro de sus límites espaciales y de los niveles sociales de sus hablantes; pertenece a la esencia del lenguaje su dialectalidad interior o diferenciación interna, y esto lo mismo se cumple en el caso de una «lengua» que en el de un "dialecto».

Un caso particular de variación lingüística lo constituye el del idioma literario: bastantes veces se ha dicho que el gran creador literario hace sa- 
biamente uso de las posibilidades del código mediante el que se expresa. La obra poética lograda posee sin duda un contenido complejo de ideaciones y sentimientos, un contenido que a ser posible tendrá la máxima generalidad humana, pero a la vez poseerá una peculiaridad formal individual que la avalora; la novedad formal individual será lo que de específico y de relieve tiene el discurso poético. Vossler advirtió esto último, y su idea ha sido más o menos repetida luego por otros estudiosos sin que nunca hayamos visto que se le ha atribuido.

El propio Karl Vossler entendió que la historia de la lengua literaria posee una inmanencia específica, que consiste en un sucederse de artificios estéticos efectivamente planteados por los grandes autores y a los que procuraron dar logro. El egregio romanista se manifestaba con un agudo párrafo:

«La Historia del arte sólo puede librarse de la miseria del diletantismo, de la mera erudición histórico-cultural y de las sutilezas psicologistas, tomando con seriedad científica y valorando las obras de arte como persistentes ensayos de resolución de problemas estéticos efectivamente planteados").

Como decimos bien puede aplicarse esto a la lengua literaria: en la serie española desde la lengua de la épica hasta la de don Juan Manuel, la de Juan de Mena, Garcilaso, Góngora, los epitalamios de la tradición sefardí, etcétera, nos encontramos con soluciones elocutivas dadas a un planteamiento estético asumido en su conciencia artística por los sucesivos creadores literarios.

Nos hallamos en definitiva con un contenido también complejo en la materia «Historia de la lengua»: evolución interna del sistema (fonología, gramática, léxico y semántica); posible correlación de ese devenir con circunstancias históricas, sociales y culturales dadas; historia de la lengua poética, de sus realizaciones efectivas tal como ellas derivan de ideales estéticos; historia de las ideas lingüisticas en su efectiva incidencia en la marcha del idioma y como documento de la propia evolución idiomática;...A todos estos aspectos sólo será posible atender si se integran - según enseñaba Menéndez Pidal por ejemplo, o también Roman Jakobson-, las perspectivas lingüística, literaria e histórica.

[En pruebas estas páginas hemos encontrado una preciosa exposición de la "Gramática histórica»: R. Lapesa, Formación e historia de la lengua española, Madrid, 1943]. 